\title{
USO DE Azospirillum brasilense PARA O AUMENTO DA EFICIÊNCIA DA ADUBAÇÃO NITROGENADA EM MILHO
}

\author{
FABIANO BERNARDO MATOS ${ }^{1}$, FELIPE FRANCO DE OLIVEIRA ${ }^{1}$, MARIZANE PIETROSKI ${ }^{1}$, \\ PRISCILA FERNANDA MULLER ${ }^{1}$, VANESSA TAKESHITA ${ }^{1}$ e GUSTAVO CAIONE ${ }^{2}$
}

${ }^{\text {I} G r a d u a n d o ~ e m ~ E n g . ~ A g r o n o ̂ m i c a, ~ U n i v e r s i d a d e ~ d o ~ E s t a d o ~ d e ~ M a t o ~ G r o s s o, ~ A l t a ~ F l o r e s t a-M T, ~ f a b i a n o b e r n a r d o m a t o s @ h o t m a i l . c o m, ~}$ felipefrancodeoliveira@hotmail.com,agro_pietroski@hotmail.com,priffmuller@hotmail.com,vanessa_takeshita@hotmail.com; ${ }^{2}$ Professor Adjunto, Universidade do Estado de Mato Grosso, Alta Floresta-MT, gcaione@unemat.br

$\overline{\text { Revista Brasileira de Milho e Sorgo, v.16, n.1, p. 131-141, } 2017}$

\begin{abstract}
RESUMO - Objetivou-se com este trabalho avaliar o efeito da adubação nitrogenada em cobertura na presença e na ausência de bactérias do gênero Azospirillum brasilense em milho safrinha. O experimento foi realizado na safrinha de 2015, em um solo classificado como Latossolo Vermelho Amarelo distrófico, no município de Alta Floresta-MT. O delineamento experimental utilizado foi em blocos ao acaso, em arranjo fatorial 4 x 2, com quatro repetições. Os tratamentos consistiram de ausência e presença de Azospirillum e quatro doses de $\mathrm{N}$ em cobertura $(0,35,70,105$ $\left.\mathrm{kg} \mathrm{ha}^{-1}\right)$. Foram avaliados a altura de plantas, a altura de inserção da espiga, o comprimento de entrenó, o diâmetro do colmo, o comprimento da espiga, o diâmetro da espiga, a massa de sabugo, o diâmetro do sabugo, o número de grãos por fileira e o número de fileiras por espiga, a massa de 100 grãos e a produtividade de grãos. Na associação de Azospirillum com N, houve incremento linear no diâmetro do colmo e no número de grãos por fileira. As doses de $\mathrm{N}$ em cobertura apresentaram ajuste quadrático, em que a produtividade aumentou em $15 \%$ com a dose de $69,33 \mathrm{~kg} \mathrm{ha}^{-1}$ de $\mathrm{N}$ em cobertura.
\end{abstract}

Palavras-chave: inoculante, Zea mays L., nitrogênio.

\section{USE OF Azospirillum brasilense TO INCREASE THE EFFICIENCY OF NITROGEN FERTILIZATION ON CORN}

\begin{abstract}
This study aims to evaluate the effect of nitrogen fertilization in top dress with and without the Azospirillum brasilense bacteria with interim-harvest of corn. The experiment was completed during 2015's interim harvest on a soil classified as Distrophic Red Yellow Latosol in Alta Floresta, MT. The experiment was conducted using a $4 \times 2$ factorial arrangement in random blocks, with four repetitions. The treatments were both with and without the Azospirillum and four doses of top dress Nitrogen $\left(0,35,70,105 \mathrm{~kg} \mathrm{ha}^{-1}\right)$. Were evaluated the plant's height, the ear of the corn insertion height, the length of the internode, the diameter of the stalks, the length of the ear, the diameter of the ear, the corncob mass, the corncob diameter, the number of kernels per row and the rows per corncob, the 100 kernels weight and the kernels productivity. In the association between Azospirillum and nitrogen, there was linear increase at the diameter of the stalks and the numbers of kernels per row. The dosage of top dress nitrogen promoted an increase of $15 \%$ at the production with $69.33 \mathrm{~kg} \mathrm{ha}^{-1}$ of nitrogen in topdress.
\end{abstract}

Keywords: inoculant, Zea mays, nitrogen. 
O milho (Zea mays L.) vem sendo cultivado durante muito tempo pelo homem, desempenhando papel fundamental no sistema de produção de alimentos. O elevado potencial produtivo, a composição química e o valor nutritivo tornam o milho um dos mais importantes cereais produzidos. É utilizado na indústria, na alimentação humana e na alimentação animal (Vorpagel, 2010).

$\mathrm{Na}$ região do Cerrado, o milho geralmente é cultivado em segunda safra (safrinha), com reduzidas doses de fertilizante nitrogenado, por suceder o plantio da soja, aproveitando o nitrogênio $(\mathrm{N})$ dos restos culturais. Dessa forma, a manutenção dos estoques de $\mathrm{N}$ do solo, nessa região, depende de um sistema simbiótico altamente eficiente para a cultura da soja e do eficiente uso de fertilizantes nitrogenados pelas culturas, especialmente milho e algodão (Alves et al., 2006).

A preocupação crescente da sociedade com a preservação e a conservação ambiental resulta na busca de tecnologias para a implantação de sistemas de produção agrícola, ampliando pesquisas na área de fixação biológica de N, culminando com a descoberta de espécies de bactérias associadas às gramíneas, tanto na rizosfera como no interior das plantas (Vorpagel, 2010).

Obedecendo a todos os critérios da legislação brasileira para inoculantes, a Embrapa Soja e a Universidade Federal do Paraná (UFPR) iniciaram, há quase dez anos, um programa de seleção de estirpes de Azospirillum com bom desempenho na promoção de crescimento das plantas e adaptação às tecnologias utilizadas nas culturas de gramíneas destinadas à produção de grãos. Como resultado dessas pesquisas, seis estirpes de Azospirillum brasilense foram aprovadas por um comitê nacional reconhecido pelo Ministério da Agricultura, Pecuária e Abastecimento
(Mapa) para a produção de inoculantes comerciais (Hungria, 2011).

Bactérias diazotróficas microaeróbicas do gênero Azospirillum têm a capacidade de fixar nitrogênio em gramíneas, melhorando seu crescimento radicular e consequentemente a absorção de água e nutrientes (Bergamaschi et al., 2006), justificando a grande importância de estudos que visem avaliar as taxas de crescimento juntamente com a produtividade de milho inoculado com bactérias A. brasiliense. É possível que na presença destes microrganismos a necessidade de fertilização nitrogenada mineral seja reduzida. No entanto, não se sabe ao certo qual a melhor dose de $\mathrm{N}$ mineral a ser aplicada na presença e na ausência destes microrganismos.

No norte do Estado de Mato Grosso, o cultivo do milho vem ganhando espaço, havendo projeções de aumentos significativos em áreas cultivadas. Portanto, surge a necessidade de estabelecer doses eficientes de $\mathrm{N}$, nutriente este que tem a capacidade de promover maior influência na produtividade e no teor de proteína bruta.

O Brasil possui uma longa tradição em pesquisa com bactérias do gênero Azospirillum brasilense, estando entre os líderes mundiais em pesquisa básica com essa bactéria e desenvolvendo muitos experimentos conduzidos em campo, contudo sem muitos resultados consistentes e conclusivos sobre a eficiência agronômica de inoculantes (Hungria, 2011). Nesse sentido, há alguns trabalhos que evidenciam efeitos positivos do uso de Azospirillum brasilense na cultura do milho (Godoy et al., 2011; Portugal, 2012; Kappes et al., 2013).

Com este trabalho, objetivou-se avaliar o efeito da adubação nitrogenada em cobertura na presença e na ausência de bactérias do gênero Azospirillum brasilense em milho safrinha, na região norte de Mato Grosso. 


\section{Material e Métodos}

$\mathrm{O}$ experimento foi realizado em propriedade rural, no município de Alta Floresta-MT, na safrinha de 2015. O solo da área é classificado como Latossolo Vermelho Amarelo distrófico, segundo os critérios do SiBCS (Santos et al., 2013), e está localizado entre 9०56’33" de latitude sul e 56 $06^{\circ}$ '51" de longitude oeste, com altitude de $290 \mathrm{~m}$. Segundo a classificação de Köppen, o clima é tropical com estação seca. O período experimental foi de 02/02/2015 a 18/06/2015, e os dados climáticos (Figura 1) referentes ao período foram adquiridos na Estação Meteorológica da Universidade do Estado de Mato Grosso-UNEMAT, Câmpus Universitário de Alta Floresta.

Inicialmente efetuou-se a amostragem do solo na profundidade de $0-20 \mathrm{~cm}$ coletando 20 amostras simples para formar uma composta que apresentou as seguintes características químicas: $\mathrm{pH}\left(\mathrm{CaCl}_{2}\right)=$
5,07; Matéria Orgânica $=8,3 \mathrm{~g} \mathrm{~kg}^{-1} ; \mathrm{Ca}=1,44 \mathrm{cmol}_{\mathrm{c}}$ $\mathrm{dm}^{-3} ; \mathrm{Mg}=1,02 \mathrm{cmol}_{\mathrm{c}} \mathrm{dm}^{-3} ; \mathrm{K}=0,14 \mathrm{cmol}_{\mathrm{c}} \mathrm{dm}^{-3} ; \mathrm{P}$ $=1,23 \mathrm{mg} \mathrm{dm}^{-3} ; \mathrm{H}+\mathrm{Al}=5,36 \mathrm{cmol}_{\mathrm{c}} \mathrm{dm}^{-3}, \mathrm{CTC}=7,8$ $\mathrm{cmol}_{\mathrm{c}} \mathrm{dm}^{-3}$ e saturação por bases $=31,4 \%$.

Utilizou-se o delineamento experimental em blocos casualizados, em arranjo fatorial 4 × 2 com quatro repetições, sendo quatro doses de $\mathrm{N}$ utilizando sulfato de amônio em cobertura $(0,35,70$ e $140 \mathrm{~kg}$ $\mathrm{ha}^{-1}$ ) parceladas em duas vezes (estádio vegetativo V4 e V8) na ausência e na presença de inoculação com Azospirillum brasilense.

Em todos os tratamentos foram aplicadas as mesmas doses na base de adubação no sulco do plantio: $40 \mathrm{~kg} \mathrm{ha}^{-1}$ de $\mathrm{K}_{2} \mathrm{O}$ como fonte o cloreto de potássio, $130 \mathrm{~kg} \mathrm{ha}^{-1}$ de $\mathrm{P}_{2} \mathrm{O}_{5}$ (sendo $80 \mathrm{~kg}$ em adubação de manutenção e $50 \mathrm{~kg}$ referentes à adubação corretiva gradual, parcelada em duas safras, com finalidade de aplicar $100 \mathrm{~kg} \mathrm{ha}^{-1}$ de $\mathrm{P}_{2} \mathrm{O}_{5}$ ), utilizando o superfosfato simples, e $30 \mathrm{~kg} \mathrm{ha}^{-1}$ de $\mathrm{N}$ utilizando sulfato de amô-

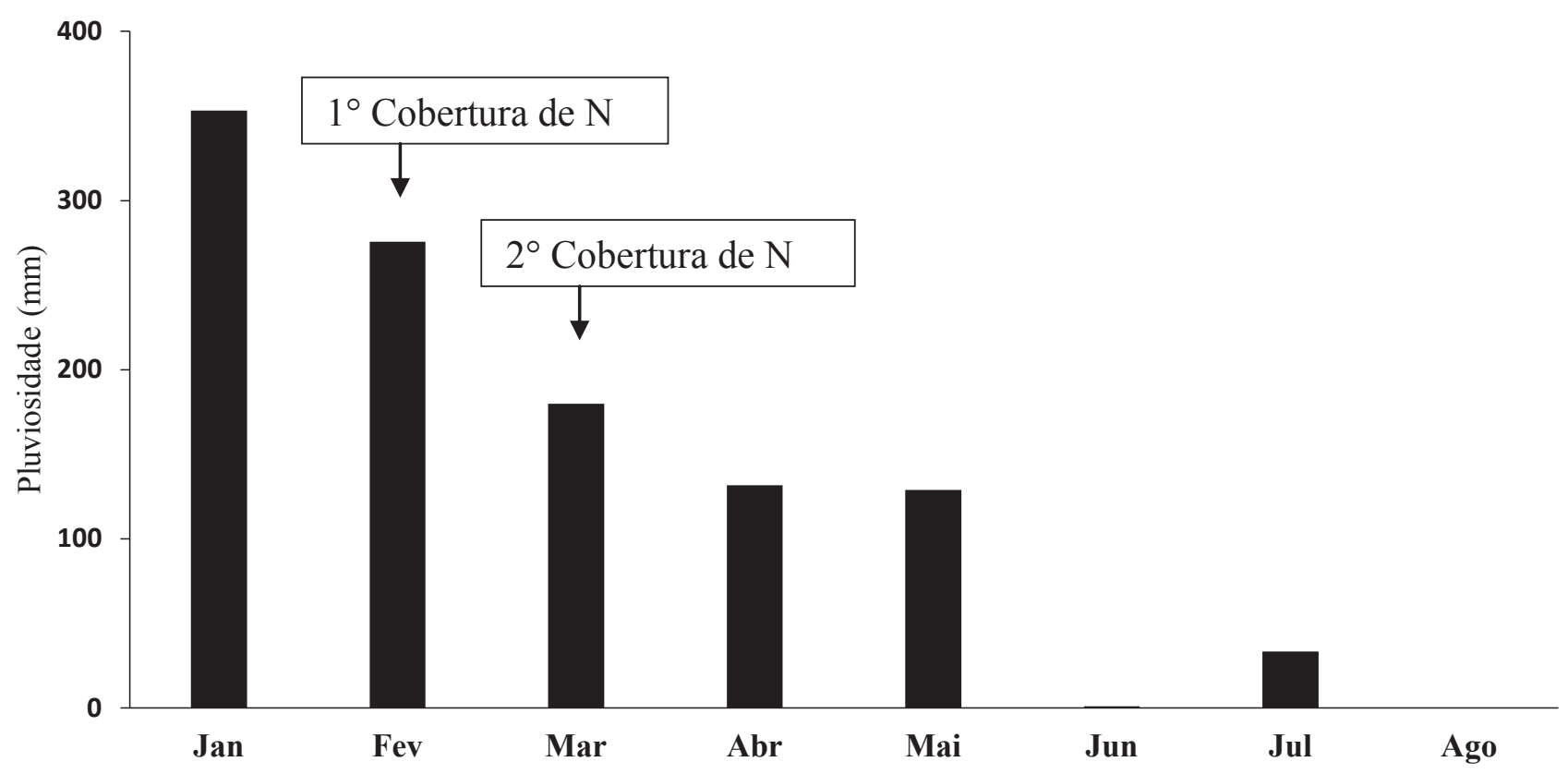

Figura 1. Índice pluviométrico de Alta Floresta-MT no período de janeiro a agosto de 2015. Fonte: Estação Meteorológica da UNEMAT, Câmpus Universitário de Alta Floresta. Alta Floresta-MT, 2015. 
nio, com expectativa de produtividade de $8 \mathrm{t} \mathrm{ha}^{-1}$. Em outubro de 2014, foi aplicado calcário na dose de 2,2 t ha ${ }^{-1}$ com intuito de elevar a saturação por bases para $60 \%$, seguido de incorporação com grade. A correção do solo e a adubação foram realizadas de acordo com recomendações de Sousa e Lobato (2004).

A parcela experimental constituiu-se de cinco linhas de semeadura com espaçamento de $0,50 \mathrm{~m}$ entre linhas e comprimento de $5 \mathrm{~m}$, totalizando área de $12,25 \mathrm{~m}^{2}$ por parcela. A semeadura foi realizada de forma manual no segundo dia do mês de fevereiro, utilizando o híbrido NS90RR2 no sistema de semeadura convencional. Tratou-se a semente com inoculante líquido formulado com as cepas Ab-V5 e Ab-V6 de Azospirillum brasilense, equivalente à dose recomendada pelo fabricante, de $100 \mathrm{~mL}$ do produto para $25 \mathrm{~kg}$ de sementes, e misturados homogeneamente dentro de um saco plástico.

Aos 30 dias após a semeadura, realizou-se o controle de insetos Diabrotica speciosa (vaquinha) com produtos de contato e ingestão à base de tiametoxam. Também foi necessária a utilização do mesmo produto em três outras aplicações no controle de percevejos.

Ao atingir a maturidade fisiológica, determinaram-se as características de crescimento (média de cinco plantas por parcela): altura média de plantas (superfície do solo até a base da inflorescência masculina), altura média de inserção de espiga (superfície do solo até o ponto de inserção da espiga), comprimento do entrenó (primeiro entrenó abaixo da inserção da espiga) e diâmetro do colmo (primeiro entrenó abaixo da inserção da espiga).

A colheita foi manual, ao atingir umidade de grãos em torno de 18\%, colhendo-se as espigas localizadas aleatoriamente nos três metros centrais de cada parcela, excluindo as duas linhas de bordadura, determinando-se o comprimento médio da espiga (região basal até a extremidade apical de cada espiga), diâmetro médio da espiga (centro da espiga), massa média de sabugo (pesagem dos sabugos secos), diâmetro do sabugo (centro do sabugo), número de grãos por fileira e de fileiras por espiga (determinados em dez espigas por parcela coletadas aleatoriamente dentro da área útil da parcela), massa de 100 grãos e produtividade de grãos (corrigidos para peso com 13\% de umidade).

Os dados obtidos foram submetidos à análise de variância pelo teste $\mathrm{F}$ e comparação de médias pelo teste de Tukey a 5\% de probabilidade para a fonte de variação qualitativa e regressão polinomial, para avaliar o efeito das doses de N, com o auxílio do programa estatístico Sisvar (Ferreira, 2011).

\section{Resultados e Discussão}

$\mathrm{Na}$ avaliação dos dados observou-se que não houve diferença significativa em relação ao comprimento do entrenó (Tabela 1). O comprimento do entrenó pode ser influenciado pela população de plantas, conforme verificado por Brachtvogel et al. (2012) quando submeteram a cultura do milho a tratamentos com diferentes populações de plantas e constataram que o aumento da população acarreta em aumento dos entrenós abaixo da inserção da espiga, em razão do estiolamento da planta em busca de luminosidade. E como no presente estudo a densidade de plantas em todos os tratamentos foi igual, este fato pode ter contribuído para a ausência de efeito sobre esta variável.

Não houve interação entre a inoculação e as doses de $\mathrm{N}$ na altura da espiga e altura da planta, porém foi significativo ao efeito das doses de $\mathrm{N}$ (Tabela 1), confirmando o efeito do nitrogênio no crescimento da planta de milho. No entanto, os dados não 
Tabela 1. Diâmetro do colmo (DC), comprimento do entrenó (CEN), altura de inserção da primeira espiga (AE) e altura de planta (AP) de milho, em função da presença ou ausência de Azospirillum e da aplicação de doses de N em cobertura. Alta Floresta-MT, 2015.

\begin{tabular}{ccccc}
\hline Doses de N (N) & DC & CEN & AE & AP \\
& mm & 14,45 & 92,06 & 230,31 \\
$\mathbf{0}$ & 13,91 & 15,12 & 99,52 & 242,49 \\
$\mathbf{3 5}$ & 15,14 & 14,15 & 93,99 & 237,38 \\
$\mathbf{7 0}$ & 15,31 & 15,28 & 98,91 & 240,75 \\
$\mathbf{1 0 5}$ & 15,07 & 14,71 & 97,59 & 240,03 \\
\hline Inoculante (I) & 14,86 & 14,79 & 94,55 & 235,43 \\
Sem & 14,85 & $2,50 \mathrm{~ns}$ & $4,58 *$ & $3,28 *$ \\
Com & $17,02 * *$ & $0,06 \mathrm{~ns}$ & $3,36 \mathrm{~ns}$ & $2,40 \mathrm{~ns}$ \\
$\mathbf{N}$ & $0,01 \mathrm{~ns}$ & $1,47 \mathrm{~ns}$ & $2,77 \mathrm{~ns}$ & $0,99 \mathrm{~ns}$ \\
\hline $\mathbf{I}$ & $5,85 * *$ & 6,53 & 5,04 & 3,53 \\
\hline $\mathbf{N ~ x ~ I ~}$ & 2,96 & &
\end{tabular}

**; * e ns: Significativo a $1 \% ; 5 \%$ de probabilidade pelo teste $\mathrm{F}$ e não significativo, respectivamente.

se adequaram às equações polinomiais testadas por apresentarem $\mathrm{R}^{2}$ muito baixos. Esse resultado é semelhante ao de Bulla e Balbinot Júnior (2012), em experimento com o uso de Azospirillum e doses de N, não encontrando efeito da interação sobre a altura da planta e altura da espiga, no entanto, efeito para doses de $\mathrm{N}$ para as duas variáveis, de modo que se constatou incremento linear nas médias com o aumento das doses aplicadas. A altura da planta está diretamente relacionada à densidade da população da cultura, sendo que plantas mais baixas toleram densidades mais altas e plantas mais altas, menores densidades. O milho aloca $50 \%$ da sua fitomassa total nos grãos ao final do ciclo, ressaltando a importância da altura da planta e da espiga, pois quanto maior for a altura da planta e maior altura da espiga, maior a susceptibilidade à quebra de colmos e tombamentos (Brachtvogel, 2008).

Houve efeito na interação entre as doses de $\mathrm{N}$ e inoculação da bactéria sobre o diâmetro do colmo
(Tabela 1). As doses de $\mathrm{N}$ sem inoculante se ajustaram à equação quadrática, tendo maior produção com aplicação de $67 \mathrm{~kg} \mathrm{ha}^{-1}$ de $\mathrm{N}$ em cobertura, com média de diâmetro de 15,69 mm (Figura 2). As doses de N com inoculante apresentaram aumento linear, estimando para cada $\mathrm{kg} \mathrm{ha}^{-1}$ de $\mathrm{N}$ em cobertura o aumento de $0,0125 \mathrm{~mm}$ no diâmetro do colmo, no intervalo da dose zero até a dose $105 \mathrm{~kg} \mathrm{ha}^{-1}$.

Avaliando o efeito da presença e ausência de inoculante sobre a média de cada dose de $\mathrm{N}$ para o diâmetro do colmo (Tabela 2), verifica-se que não há diferença entre as médias nas doses zero e 35 $\mathrm{kg} \mathrm{ha}^{-1}$. Na dose $70 \mathrm{~kg} \mathrm{ha}^{-1}$ obteve diferença significativa, apresentando aumento de $0,99 \mathrm{~mm}$ na ausência, e na dose $105 \mathrm{~kg} \mathrm{ha}^{-1}$ houve diferença entre médias, proporcionando aumento de $0,77 \mathrm{~mm}$ com a presença de inoculante. Isso demonstra que a inoculação com Azospirillum foi eficiente para o maior crescimento do diâmetro do colmo quando conjugada à maior dose de N. 


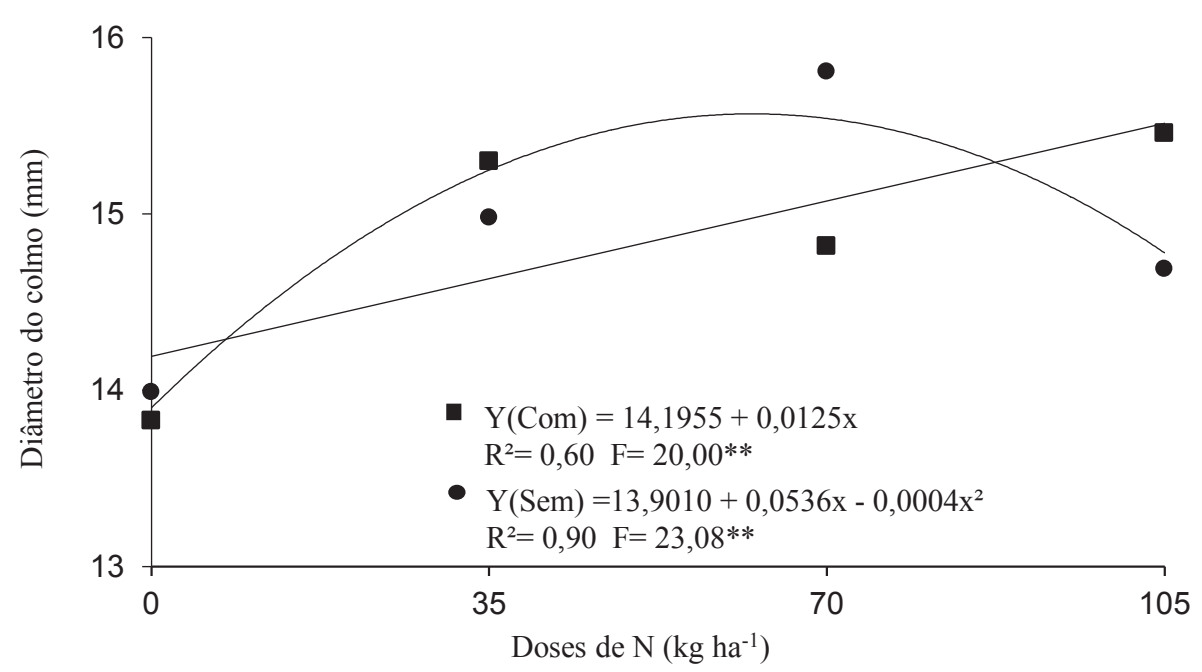

Figura 2. Diâmetro do colmo em função da interação entre doses de N e inoculante. Alta Floresta-MT, 2015.

Tabela 2. Efeito das doses de $\mathrm{N}$ na presença e na ausência de Azospirillum brasilense sobre o diâmetro do colmo na cultura do milho. Alta Floresta-MT, 2015.

\begin{tabular}{ccccc}
\hline \multirow{2}{*}{ Inoculante } & \multicolumn{5}{c}{ Doses de N } \\
\cline { 2 - 5 } Com & 0 & 35 & 70 & 105 \\
nem & $13,83 \mathrm{a}$ & $15,30 \mathrm{a}$ & $14,82 \mathrm{~b}$ & $15,46 \mathrm{a}$ \\
Sem & $13,99 \mathrm{a}$ & $14,98 \mathrm{a}$ & $15,81 \mathrm{a}$ & $14,69 \mathrm{~b}$ \\
\hline DMS $=\mathbf{0 , 6 4}$ & & &
\end{tabular}

Médias seguidas pela mesma letra na vertical não diferem entre si pelo teste de Tukey a $5 \%$ de probabilidade.

Os aumentos verificados no diâmetro do colmo das plantas de milho submetidas à inoculação de Azospirillum podem ser associados à produção de fito -hormônios, como auxinas, giberelinas e citocininas (Dartora et al., 2013), substâncias reguladoras e promotoras do crescimento vegetal, ajudando a melhorar a nutrição mineral, assim como a utilização de água pelas plantas (Domingues Neto et al., 2013).

Este efeito foi similar ao descrito por Guimarães et al. (2013), em que as plantas inoculadas com $A$. brasilense apresentaram aumentos em 8,7\% no diâmetro do colmo quando comparadas à testemunha. Trabalho realizado por Kappes et al. (2013) demonstrou grande eficiência do A. brasilense, tendo aumento significativo em todos os tratamentos quando relacionados às doses, com máximo de 22,2 mm no diâmetro do colmo. O bom desenvolvimento do colmo é essencial na produtividade do milho. Conforme Magalhães et al. (2002) descrevem, a sua atuação baseia-se diretamente na produção do milho por armazenar sólidos solúveis essenciais para garantir translocação de fotoassimilados e a formação dos grãos. É vantajoso o aumento do diâmetro do colmo com a aplicação de $\mathrm{N}$, pois esta característica morfológica é uma das que mais têm sido relacionadas com acamamento e quebramento da planta de milho (Kappes et al., 2013).

$\mathrm{Na}$ análise de grãos por fileira (Tabela 3), observa-se a interação entre dose de $\mathrm{N}$ e inoculante. As doses de $\mathrm{N}$ com inoculante se ajustaram ao modelo linear, estimando que a maior dose (105 $\left.\mathrm{kg} \mathrm{ha}^{-1} \mathrm{de} \mathrm{N}\right)$ aumenta em média 3,6 grãos por fileira quando com- 
parada à dose zero. No entanto, para o tratamento sem (2012), que observou aumento na quantidade de grãos inoculante, não houve efeito das doses de N (Figura 3), na espiga em relação ao tratamento controle, sem N. mantendo uma média de 36,36 grãos na fileira da espiAs doses de $\mathrm{N}$ em cobertura promoveram inga, obtendo-se resultados semelhantes ao de Portugal cremento com ajuste quadrático sobre a produtivida-

Tabela 3. Comprimento de espiga (CE), diâmetro de espiga (DE), diâmetro do sabugo (DS), fileiras por espiga (FE), grãos por fileira (GF), massa do sabugo (MS), massa de 100 grãos (M100) e produtividade de grãos (PR) de milho, em função da presença ou ausência de Azospirillum e da aplicação de doses de $\mathrm{N}$ em cobertura. Alta Floresta-MT, 2015.

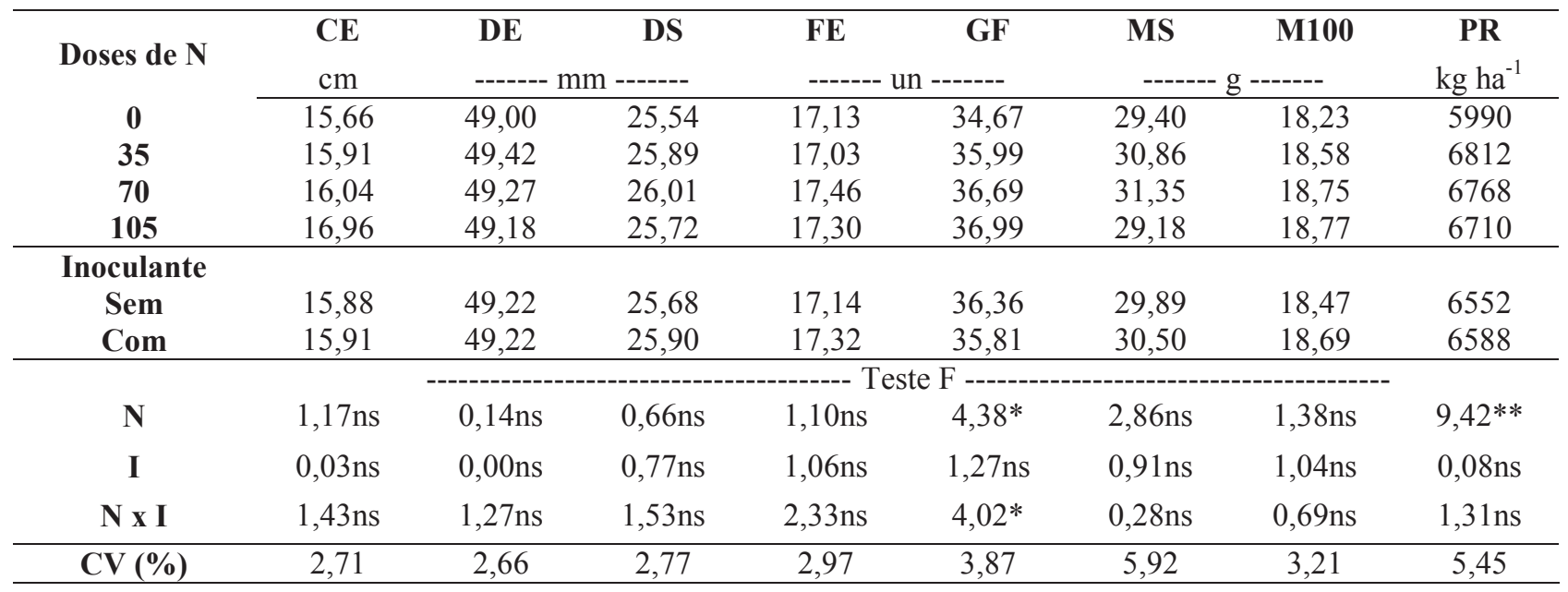

**; * e ns: Significativo a $1 \% ; 5 \%$ de probabilidade pelo teste $\mathrm{F}$ e não significativo, respectivamente.

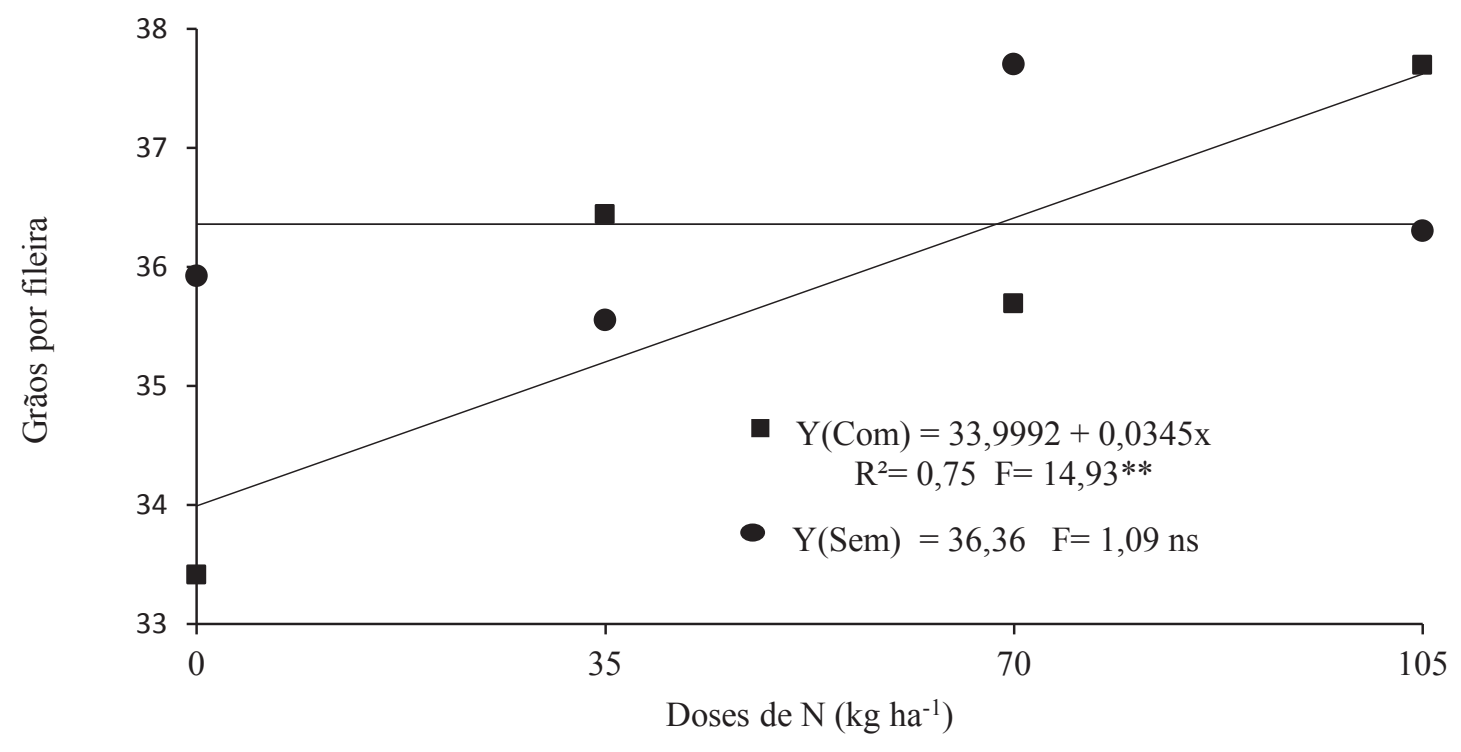

Figura 3. Grãos por fileira em função da interação entre doses de N e inoculante. Alta Floresta-MT, 2015. 
de $\left(\mathrm{kg} \mathrm{ha}^{-1}\right)$ do milho (Figura 4). Nota-se que a maior produtividade obtida foi com a dose de $69,33 \mathrm{~kg} \mathrm{ha}^{-1}$ de $\mathrm{N}$, correspondendo a $6.896 \mathrm{~kg} \mathrm{ha}^{-1}$ de grãos, obtendo incremento de $15,12 \%$ em relação ao tratamento com dose zero de $\mathrm{N}$, demonstrando melhor a curva de resposta do tratamento com dose de $\mathrm{N}$ em cobertura. Trabalho conduzido por Fernandes et al. (2005), no município de Ilha Solteira-SP, com seis variedades de milho, demonstrou eficiência do $\mathrm{N}$ na produtividade, sendo tal eficiência diminuída conforme foram aplicados altos níveis de adubação nitrogenada. Estudo realizado por Hurtado et al. (2009) no cerrado evidenciou adequação a modelos quadráticos de resposta a adubação nitrogenada, demonstrando que o aumento expressivo na dose de $\mathrm{N}$ pode incorrer na diminuição da produtividade por causa do excesso de adubação.

Não houve interação entre nitrogênio e Azospirillum na produtividade, possivelmente pela diminuição da comunidade de bactérias $A$. brasilense nas raízes do milho com aumento da dose de $\mathrm{N}$, fato esse observado por Bergamaschi (2006) com experimento em vasos no município de Porto Alegre-RS, que analisou o efeito das doses de $\mathrm{N}$ associados à inoculação de Azospirillum em cultivar de sorgo forrageiro. A conclusão de Bergamaschi (2006) provavelmente ocorreu pelo fato de a escolha do genótipo da planta associada à seleção correta das estirpes significar fatores para obtenção dos benefícios da fixação biológica de N, não sendo eficientes para todas as gramíneas em geral (Hungria, 2011). Fator também associado à diferença de ambiente, explicando que as estirpes quando submetidas a campo sofrem competição com bactérias diazotróficas nativas e com a microflora geral do solo, diferente das submetidas a experimento em vasos, onde não há grande competição entre os fatores do ambiente.

Comparando o efeito do inoculante na produtividade do milho, foi concluído que não houve diferença significativa, fato ressaltado por Godoy et al. (2011) no experimento realizado em Campo Mourão -PR, onde se observou a não significância do efeito na inoculação de Azospirillum na produtividade do milho. No entanto, em experimento conduzido em Teresina-PI, no ano de 2011/2012, foi demonstrada

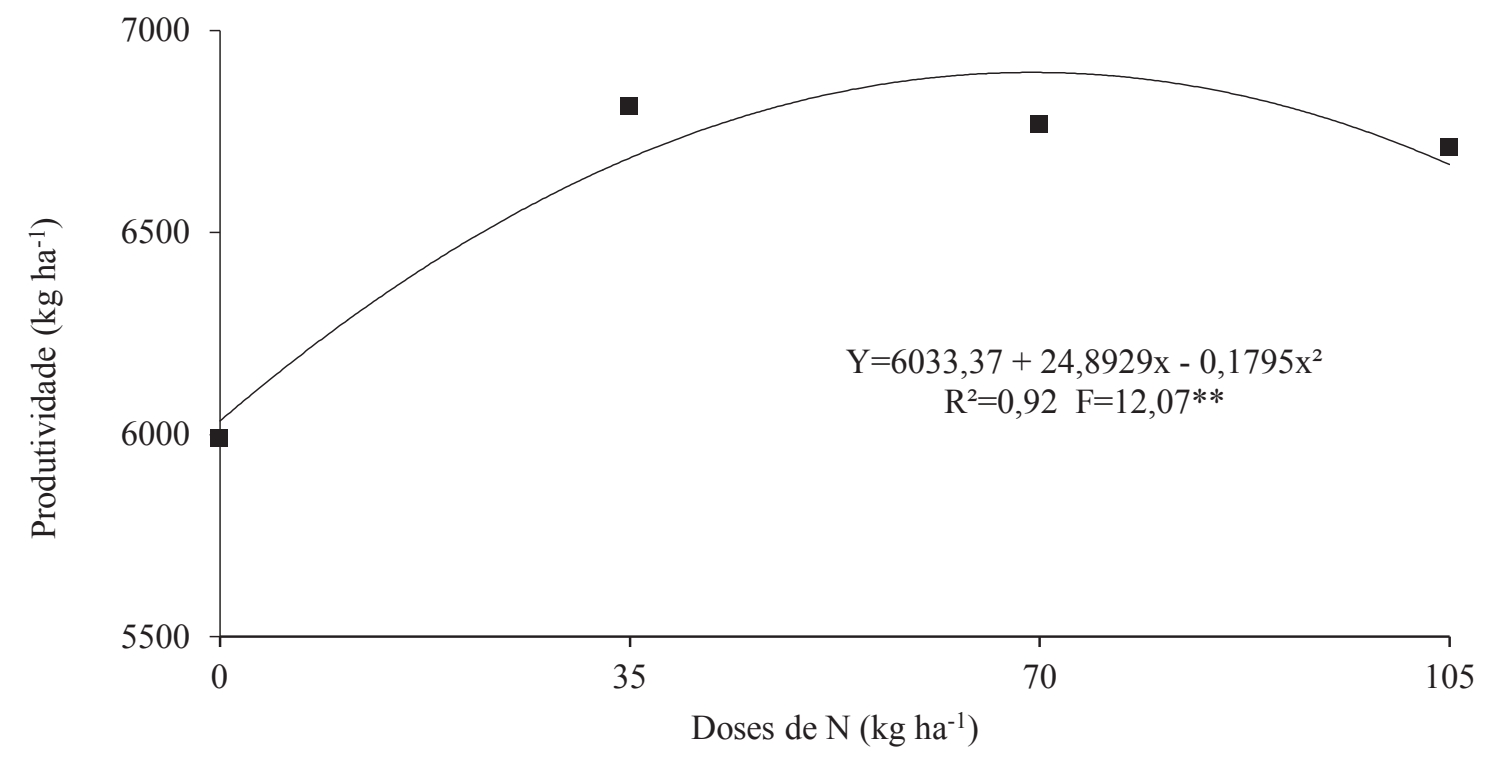

Figura 4. Produtividade do milho em função das doses de N aplicadas. Alta Floresta-MT, 2015. 
a eficiência de Azospirillum com incremento na produção, sendo esta superior a 30\% em relação ao tratamento controle sem inoculação (Araújo et al., 2014).

Os efeitos de inoculação com Azospirillum dependem das características genéticas de cada variedade a ser implantada e das estirpes, além da necessidade de ambiente favorável, clima e temperaturas adequadas que favoreçam a bactéria a se desenvolver (Braccini et al., 2012). Portanto, surge a necessidade de mais pesquisas avaliando o efeito desses fatores sobre a eficiência da inoculação.

Melhores resultados se observam em culturas de médio a baixo investimento, em que o rendimento da lavoura não é alto (Hungria, 2011). Vogt et al. (2014) também ressaltaram que o investimento, além de ser de baixo custo, é de baixo impacto ambiental e há necessidade de aprimorar técnicas para reduzir as doses de fertilizantes nitrogenados, mesmo testando em seu experimento quatro cultivares de milho que não obtiveram resultados significativos em relação à produtividade.

Analisando os componentes de produção CE, DE, DS, FE, MS e M100 (Tabela 3), observa-se que não houve diferenças significativas para nenhuma dessas variáveis.

A ausência de efeito dos tratamentos sobre alguns componentes pode estar associada às intensas chuvas ocorridas durante o período vegetativo da cultura, chegando a $275 \mathrm{~mm}$ em fevereiro e coincidindo com o período de primeira cobertura com N e 179 $\mathrm{mm}$ de chuva acumulada no mês de março, período da segunda cobertura de N (Figura 1), podendo haver perda de $\mathrm{N}$ por lixiviação. Este período é fundamental para a adequada nutrição nitrogenada, pois é quando a planta necessita de $\mathrm{N}$ para definir todos os componentes de produção, como evidenciado no experimento conduzido por Schiavinatti et al. (2011), constatando que precipitações elevadas no início do ciclo de cultivo afetaram a eficiência da dose de $\mathrm{N}$ em cobertura. Outro fator a ser considerado é a interferência do N no processo de fixação na rizosfera da planta, como descrito por Silva et al. (2007), relatando que a adubação nitrogenada em gramíneas submetidas a inoculação com bactérias fixadoras de nitrogênio pode impedir a fixação biológica quando a competição existente entre as bactérias diazotróficas com outras bactérias do meio é muito alta, sintetizando maior quantidade de $\mathrm{N}$ no complexo nitrogenase. Quando submetidas a doses de $\mathrm{N}$ mineral altas, as bactérias interrompem a síntese do complexo nitrogenase e passam a utilizar o $\mathrm{N}$ disponível do solo.

Neste trabalho, não se constatou efeito isolado dos tratamentos com Azospirillum brasilense na produtividade da cultura do milho, demonstrando necessidade de aperfeiçoar essa tecnologia para melhorar o desempenho agronômico da cultura do milho na região norte de Mato Grosso.

\section{Conclusões}

Não houve efeito do Azospirillum na cultura do milho, obtendo-se respostas apenas na interação com nitrogênio para diâmetro do colmo e grãos por fileira.

A aplicação de 69,33 $\mathrm{kg} \mathrm{ha}^{-1}$ de $\mathrm{N}$ em cobertura proporciona aumento de produtividade de grãos na cultura do milho em $15,12 \%$, em relação à ausência de aplicação de $\mathrm{N}$ em cobertura, independentemente do uso de Azospirillum.

\section{Referências}

ALVES, B. J. R.; ZOTARELLI, L.; FERNANDES, F. M.; HECKLER, J. C.; MACEDO, R. A. T.; BODDEY, R. M.; JANTALIA, C. P. Fixação biológica de nitrogênio 
e fertilizantes nitrogenados no balanço de nitrogênio em soja, milho e algodão. Pesquisa Agropecuária Brasileira, Brasília, DF, v. 41, n. 3, p. 449-456, 2006.

DOI: 10.1590/S0100-204X2006000300011.

ARAÚJO, R. M.; ARAÚJO, A. S. F.; NUNES, L. A. P. L.; FIGUEIREDO, M. V. B. Resposta do milho verde à inoculação com Azospirillum brasilense e níveis de nitrogênio. Ciência Rural, Santa Maria, v. 44, n. 9, p. 1556-1560, 2014. DOI: 10.1590/0103-8478cr20130355.

BERGAMASCHI, C. Bactérias diazotróficas associadas as raízes e colmos de cultivares de sorgo. 2006. $71 \mathrm{f}$. Dissertação (Mestrado em Microbiologia Agrícola e do Ambiente) - Universidade Federal do Rio Grande do Sul, Porto Alegre, 2006.

BERGAMASCHI, H.; DALMAGO, G. A.; COMIRAN, F.; BERGONCI, J. I.; MULLER, A. G.; FRANÇA, S.; SANTOS, A. O.; RADIN, B.; BIANCHI, C. A. M.; PEREIRA, P. G. Déficit hídrico e produtividade na cultura do milho. Pesquisa Agropecuária Brasileira, Brasília, DF, v. 41, n. 2, p. 243-249, 2006.

DOI: 10.1590/S0100-204X2006000200008.

BRACCINI, A. L.; DAN, L. G. M.; PICCININ, G. G.; ALBRECHT, L. P.; BARBOSA, M. C.; ORTIZ, A. H. T. Seed Inoculation with Azospirillum brasilense, associated with the use of bioregulators in maize. Revista Caatinga, Mossoró, v. 25, n. 2, p. 58-64, 2012.

BRACHTVOGEL, E. L. Densidades e arranjos populacionais de milho e componentes agronômicos. 2008. 96 f. Dissertação (Mestrado em Agronomia) Universidade Estadual Paulista "Júlio de Mesquita Filho", Botucatu, 2008.

BRACHTVOGEL, E. L.; PEREIRA, F. R. da S.; CRUZ, S. C. S.; ABREU, M. L. de; BICUDO, S. J. População, arranjo de plantas uniforme e a competição intraespecífica em milho. Revista Trópica: Ciências Agrárias e Biológicas, Confresa, v. 6, n. 1, p. 75-82, 2012.

BULLA, D.; BALBINOT JÚNIOR, A. A. Inoculação de sementes de milho com Azospirillum brasilense em diferentes doses de nitrogênio. Agropecuária Catarinense, Florianópolis, v. 25, n. 2, p. 61-63, 2012.

DARTORA, J.; GUIMARÃES, V. F.; MARINI, D.; SANDER, G. Adubação nitrogenada associada à inoculação com Azospirillum brasilense e Herbaspirillum seropedicae na cultura do milho. Revista Brasileira de Engenharia Agrícola e Ambiental, Campina Grande, v. 17, n. 10, p. 1023-1029, 2013.

DOI: $10.1590 /$ S1415-43662013001000001.

DOMINGUES NETO, F. J.; YOSHIMI, F. K.; GARCIA, R. D.; MIYAMOTO, Y. R.; DOMINGUES, M. C. S. Desenvolvimento e produtividade do milho verde safrinha em resposta à aplicação foliar com Azospirillum brasilense. Enciclopédia Biosfera, Goiânia, v. 9, n. 17, p. 1030-1040, 2013.

FERNANDES, F. C. S.; BUZETTI, S.; ARF, O.; ANDRADE, J. A. C. Doses, eficiência e uso de nitrogênio por seis cultivares de milho. Revista Brasileira de Milho e Sorgo, Sete Lagoas, v. 4, n. 2, p. 195-204, 2005. DOI: 10.18512/1980-6477/rbms.v4n2p195-204.

FERREIRA, D. F. Sisvar: a computer statistical analysis system. Ciência e Agrotecnologia, Lavras, v. 35, n. 6, p. 1039-1042, 2011.

DOI: $10.1590 / \mathrm{S} 1413-70542011000600001$.

GODOY, J. C.; WATANABE, S. H.; FIORI, C. C. L.; GUARIDO, R. C. Produtividade de milho em resposta a doses de nitrogênio com e sem inoculação das sementes com Azospirillum brasilense. Campo Digital, Campo Mourão, v. 6, n. 1, p. 26-30, 2011.

GUIMARÃES, S. L.; MOREIRA, J. C. F.; BONFIMSILVA, E. M.; POLIZEL, A. C.; SABINO, D. C. C. Características produtivas de plantas de milho inoculadas com Azospirillum spp. cultivadas em Latossolo de cerrado. Enciclopédia Biosfera, Goiânia, v. 9, n. 16, p. 558-567, 2013.

HUNGRIA, M. Inoculação com Azospirillum brasilense: inovação em rendimento a baixo custo. Londrina: Embrapa Soja, 2011. 36 p. (Embrapa Soja. Documentos, 325). 
HURTADO, S. M. C.; RESENDE, A. V. de; SILVA, C. A.; CORAZZA, E. J.; SHIRATSUCHI, L. S. Variação espacial da resposta do milho à adubação nitrogenada de cobertura em lavoura no Cerrado. Pesquisa Agropecuária Brasileira, Brasília, DF, v. 44, n. 3, p. 300-309, 2009. DOI: 10.1590/S0100-204X2009000300012.

KAPPES, C.; ARF, O.; ARF, M. V.; FERREIRA, J. P.; DAL BEM, E. A.; PORTUGAL, J. R.; VILELA, R. G. Inoculação de sementes com bactéria diazotrófica e aplicação de nitrogênio em cobertura e foliar em milho. Semina: Ciências Agrárias, Londrina, v. 34, n. 2, p. 527 538, 2013. DOI: 10.5433/1679-0359.2013v34n2p527.

MAGALHÃES, P. C.; DURÃES, F. O. M.; CARNEIRO, N. P.; PAIVA, E. Fisiologia do milho. Sete Lagoas: Embrapa Milho e Sorgo, 2002. 23 p. (Embrapa Milho e Sorgo. Circular Técnica, 22).

PORTUGAL, A. V. Fontes de nitrogênio no cultivo de milho em sistema plantio direto: avaliação econômica e produtividade. 2012. 66 f. Dissertação (Mestrado em Sistema de Produção na Agropecuária) - Universidade José do Rosário Vellano, Alfenas, 2012.

SANTOS, H. G. dos; JACOMINE, P. K. T.; ANJOS, L. H. C. dos; OliVEIRA, V. A. de; LUMBRERAS, J. F.; COELHO, M. R.; ALMEIDA, J. A. de; CUNHA, T. J. F.; OLIVEIRA, J. B. de. Sistema brasileiro de classificação de solos. 3. ed. rev. e ampl. Brasília, DF: Embrapa, 2013. $353 \mathrm{p}$.
SCHIAVINATTI, A. F.; ANDREOTTI, M.; BENETT, C. G. S.; PARIZ, C. M.; LODO, B. N.; BUZETTI, S. Influência de fontes e modos de aplicação de nitrogênio nos componentes da produção e produtividade do milho irrigado no Cerrado. Bragantia, Campinas, v. 70, n. 4, p. 295-230, 2011.

DOI: $10.1590 /$ S0006-87052011000400027.

SILVA, D. M.; ANTONIOLLI, A. I.; JACQUES, R. J. S.; VOSS, M. Bactérias diazotróficas nas folhas e colmos de plantas dearrozirrigado(Orizasativa L.). Revista Brasileira de Agrociência, Pelotas, v. 13, n. 2, p. 181-187, 2007.

SOUSA, D. M. G.; LOBATO, E. Cerrado: correção do solo e adubação. 2. ed. Brasília, DF: Embrapa Informação Tecnológica;Planaltina,DF:EmbrapaCerrados,2004.416p.

VOGT, G. A.; BALBINOT JÚNIOR, A. A.; GALLOTTI, G. J. M.; PANDOLFO, C. M.;ZOLDAN, S. R. Desempenho de genótipos de milho na presença ou ausência de inoculação com Azospirillum brasilense e adubação nitrogenada de cobertura. Agropecuária Catarinense, Florianópolis, v. 27, n. 2, p. 49-54, 2014.

VORPAGEL, A. G. Inoculação de Azospirillum, Isolado e associado a bioestimulante, em milho no Noroeste do RS. 2010. 55 f. Monografia (Graduação em Agronomia) - Universidade Regional do Noroeste do Estado do Rio Grande do Sul, Ijuí-RS, 2010. 